\title{
Assessing large-scale weekly cycles in meteorological variables: a review
}

\author{
A. Sanchez-Lorenzo ${ }^{1}$, P. Laux ${ }^{2}$, H.-J. Hendricks Franssen ${ }^{3}$, J. Calbó ${ }^{4}$, S. Vogl ${ }^{2,5}$, A. K. Georgoulias ${ }^{6}$, and J. Quaas ${ }^{7}$ \\ ${ }^{1}$ Institute for Atmospheric and Climate Science (IAC), Swiss Federal Institute of Technology Zürich (ETH Zürich), Zürich, \\ Switzerland \\ ${ }^{2}$ Institute for Meteorology and Climate Research (IMK-IFU), Karlsruhe Institute of Technology (KIT), \\ Garmisch-Partenkirchen, Germany \\ ${ }^{3}$ Agrosphere Institute (IBG-3), Forschungszentrum Jülich GmbH, Jülich, Germany \\ ${ }^{4}$ Departament de Física, Universitat de Girona, Girona, Spain \\ ${ }^{5}$ Institute for Geography, Regional Climate and Hydrology, University of Augsburg, Augsburg, Germany \\ ${ }^{6}$ Laboratory of Atmospheric Pollution and Pollution Control Engineering of Atmospheric Pollutants, Department of \\ Environmental Engineering, Democritus University of Thrace, Xanthi, Greece \\ ${ }^{7}$ Institute for Meteorology, University of Leipzig, Leipzig, Germany
}

Correspondence to: A. Sanchez-Lorenzo (arturo.sanchez@env.ethz.ch)

Received: 16 November 2011 - Published in Atmos. Chem. Phys. Discuss.: 16 January 2012

Revised: 11 June 2012 - Accepted: 12 June 2012 - Published: 3 July 2012

\begin{abstract}
Several studies have claimed to have found significant weekly cycles of meteorological variables appearing over large domains, which can hardly be related to urban effects exclusively. Nevertheless, there is still an ongoing scientific debate whether these large-scale weekly cycles exist or not, and some other studies fail to reproduce them with statistical significance. In addition to the lack of the positive proof for the existence of these cycles, their possible physical explanations have been controversially discussed during the last years. In this work we review the main results about this topic published during the recent two decades, including a summary of the existence or non-existence of significant weekly weather cycles across different regions of the world, mainly over the US, Europe and Asia. In addition, some shortcomings of common statistical methods for analyzing weekly cycles are listed. Finally, a brief summary of supposed causes of the weekly cycles, focusing on the aerosol-cloud-radiation interactions and their impact on meteorological variables as a result of the weekly cycles of anthropogenic activities, and possible directions for future research, is presented.
\end{abstract}

\section{Introduction}

There is an increasing consensus about the anthropogenic impact on the recent change of the Earth's climate. The global mean near surface air temperature has risen by $0.74 \pm 0.18 \mathrm{~K}$ over the last century (1906-2005 period); with a warming rate over the last decades that has no precedent in the instrumental records. This trend is projected to continue in the future; nevertheless, climate projections are still affected by important uncertainties, especially related with the role of aerosols and clouds in the climate system (Solomon et al., 2007).

Because there is no evidence of natural processes with weekly cycles (hereafter referred to as WCs), the study of such cycles in meteorological variables has become an interesting way to establish links between human activities and their influence on the climate. It is well known that humaninduced activities (e.g. commercial transportation, industrial activity, etc.) are commonly reduced during weekends compared to weekdays, especially in the western industrialised countries. Consequently, if the mean values of meteorological variables show a WC, these variations might be linked to a human impact and considered as an anthropogenic signal. 
The study of WCs of different meteorological and air pollution variables has become a common practice for detecting local climate modification in "urban" areas. Studies go back until 1929 (e.g. Ashworth, 1929) and an increased activity during the 50's and 60's of the 20th century (e.g. see review in Lawrence, 1971; Kanda, 2007) was observed. These previous studies focused on the impact of human activities near the major sources of heat and air pollution emissions, which are mainly concentrated in urban, semi-urban and industrial areas. More recently, there is an ongoing interest in the study of WCs of atmospheric pollutants and different meteorological variables in large-scale domains that can hardly be related to local or urban effects exclusively. This possible impact of WCs of human activities on weather and climate modification over larger scales is still not clear. A different mechanism is required in order to explain the "large-scale" WCs, being the most common approach to link these changes, i.e. through atmospheric interactions at the mesoscale, with direct and indirect aerosol effects (see Sect. 4.2.2). This paper will focus on a review of studies about "large-scale" WCs (for a review of urban WC's see Arnfield, 2003 and Kanda, 2007), which is a more recent topic in scientific literature, thus holding major uncertainties and some confusion. Also, to our knowledge, a review of this subject is still lacking. It is also important to clarify the terminology since during the last years different terms have been used for periodic variations of meteorological variables on the weekly scale: weekly periodicity, weekly cycles, day of the week variations, or weekend effect. In fact, these terms are often used synonymously; however, weekend effect implies that the analysis is designed to find significant differences between the weekend and the working week, normally using the Saturday through Monday and Wednesday through Friday periods to define both periods respectively. This implies that both periods are considered as independent populations. The terms weekly periodicity or weekly cycle are used with two different meanings: (i) the variation of day-of-the-week averages can be described approximately by a sinusoidal function with a period of exactly seven days and (ii) one or more weekdays is/are on average significantly different compared to the rest of the week. In this review we will use preferably the expression "large-scale" WCs or simply WCs to describe differences in the analysed variables within the week as a consequence of a possible periodic signal in the data.

The main objective of the paper is to show a comprehensive review of existing studies about WCs classified by regions (i.e. US, Europe and Asia) and for meteorological variables such as temperature, rainfall, cloudiness, etc. The second objective is to summarise the methods for detecting and proving the existence of the WCs which are currently in use and to discuss their advantages and limitations. The current paper is structured as follows: after this introduction, Sect. 2 presents a summary of the literature on the subject that is currently available. Section 3 is dedicated to the main uncertainties remaining in the statistical tests of the WCs.
In Sect. 4 potential causes and mechanisms for large-scale WCs are discussed. In Sect. 5 possible directions for future research of WCs are suggested, and Sect. 6 gives some concluding remarks.

\section{Studies about large-scale WCs}

In this section the main results about large-scale WCs published until now are presented. Table 1 summarizes the details of the reviewed publications, i.e. study region, variables used, significance of the results, and statistical level of significance (if provided).

\subsection{Milestones in the history of the "non-urban" WCs}

The start of the "large-scale" WCs studies can be dated back to the early 1990s when a paper entitled "Weekdays warmer than weekends?" was published in Nature (Gordon, 1994). In this paper Gordon analysed global temperatures, for the lower troposphere (integrated between $1000 \mathrm{hPa}$ and $400 \mathrm{hPa}$ levels), recorded by NOAA satellites between 1979 and 1992. His results showed significant temperature differences reaching $\pm 0.02 \mathrm{~K}$ between Wednesday and Sunday in the Northern Hemisphere, whereas no significant differences were found for the Southern Hemisphere. Although the analysis was limited to the mean for the land and ocean data, and no spatial representation of the differences along the week was shown, Gordon concluded that the detected WC in the Northern Hemisphere temperatures should be considered as a possible heat signal from human-induced activities. Few months later Lenschow (1994) published a comment to Gordon's (1994) work, pointing out the weaknesses of the human-induced heat signal suggested by Gordon (1994). On the other hand, Lenschow suggested expanding the analyses by using different variables and data sets, highlighting the importance to improve our knowledge about the anthropogenic effects on the climate system. Note that Gordon suggests weekdays warmer than weekends which he implicitly attributed to an enhanced greenhouse effect during weekdays, and which would be opposite to an anthropogenic cooling during weekdays via enhanced aerosols.

Afterwards, Cerveny and Balling (1998) analysed different independent datasets over the Atlantic coast of the US and neighboring oceanic areas, concluding that WCs can be observed in the rainfall and tropical cyclones activity, possibly linked to the downwind pollution transport from the urbanised eastern seaboard of the United States. Five years later, Forster and Solomon (2003) analysed surface diurnal temperature range (DTR) over the major part of the Northern and also in some areas of the Southern Hemisphere (e.g. Australia). They clearly showed significant differences between the weekends and central weekdays in different areas, especially across the US, however, the identified patterns are not spatially coherent neither in magnitude nor in sign. After 
Table 1. Summary of the reviewed studies, including information regarding the region studied, the type of data, period, variables and temporal resolution. If significant WCs are reported, also the statistical level of confidence is given (if provided by author(s)), as well as the reliability of the statistical analysis used in the manuscripts.

\begin{tabular}{|c|c|c|c|c|c|c|c|c|}
\hline Region & Reference & Data $^{a}$ & Period & Variables $^{\mathrm{b}}$ & Temporal $^{\mathrm{c}}$ & Cycles & Sig & Reliability $^{\mathrm{d}}$ \\
\hline Global & Gordon (1994) & RS & 1979-1992 & $\mathrm{T}$ & A & Yes & $p \leq 0.10$ & $\downarrow$ \\
\hline Global (land) & Forster and Solomon (2003) & SO & 1980s-1990s & $\mathrm{T}$ & A & Yes & $p \leq 0.05$ & - \\
\hline Northern Hemisphere & Tesouro et al. (2005) & $\mathrm{RE}$ & 1958-2001 & $\mathrm{T}$ & A & Yes & $p \leq 0.05$ & - \\
\hline North America & Forster and Solomon (2003) & SO & 1940s-1990s & $\mathrm{T}$ & $\mathrm{A}, \mathrm{W}, \mathrm{S}$ & Yes & $p \leq 0.05$ & - \\
\hline North America & Kim et al. (2010) & $\mathrm{SO}, \mathrm{RE}$ & $1940 \mathrm{~s}-2000 \mathrm{~s}$ & $\mathrm{~T}$ & $\mathrm{~S}$ & Yes & ? & - \\
\hline Southern North America & Bell et al. (2008) & $\mathrm{RS}, \mathrm{SO}, \mathrm{RE}$ & 1998-2005 & $\mathrm{R}$ & $\mathrm{S}$ & Yes & $p \leq 0.05$ & $\uparrow$ \\
\hline Southern North America & Rosenfeld and Bell (2011) & SO & 1995-2009 & Tornado, Hail & $S$ & Yes & $p \leq 0.01$ & $\uparrow$ \\
\hline United States & Tuttle and Carbone (2011) & RS, SO & 1996-2007 & $\mathrm{R}$ & $S$ & Yes & $p \leq 0.01$ & $\uparrow$ \\
\hline United States & Schultz et al.(2007) & SO & 1951-1992 & $\mathrm{P}$ & A, S & No & - & $\downarrow$ \\
\hline SE United States & Cerveny and Balling (1999) & $\mathrm{RS}, \mathrm{SO}$ & 1940s-1990s & $\mathrm{R}, \mathrm{W}$ & A & Yes & $p \leq 0.05$ & - \\
\hline Atlantic Basin & Cerveny and Balling (2005) & SO & 1970-2003 & $\mathrm{W}$ & A & Yes & $p \leq 0.05$ & - \\
\hline Northeast US & DeLisi et al. (2001) & SO & 1973-2002 & $\mathrm{P}$ & $\mathrm{A}$ & No & - & - \\
\hline Phoenix, US & Svoma and Balling (2009) & SO & 1980-2007 & $\mathrm{R}$ & $\mathrm{W}$ & Yes & $p \leq 0.01$ & - \\
\hline China & Gong et al. (2006) & $\mathrm{SO}, \mathrm{RE}$ & $1979-2000$ & $\mathrm{~T}, \mathrm{R}, \mathrm{H}, \mathrm{R}$ & $\mathrm{A}, \mathrm{W}, \mathrm{S}$ & Yes & $p \leq 0.10$ & $\downarrow$ \\
\hline China & Gong et al. (2007) & SO, RE & $2001-2006$ & $\mathrm{~T}, \mathrm{R}, \mathrm{W}$ & $\mathrm{S}$ & Yes & $p \leq 0.10$ & $\uparrow$ \\
\hline China & Choi et al. (2008a) & SO, RE & $2001-2005$ & $\mathrm{R}, \mathrm{W}, \mathrm{C}, \mathrm{P}$ & A & Yes & $p \leq 0.01$ & - \\
\hline China & Ho et al. (2009) & SO & $1980-2005$ & $\mathrm{~T}, \mathrm{R}, \mathrm{C}, \mathrm{H}$ & $S$ & Yes & $p \leq 0.05$ & $\downarrow$ \\
\hline Tibet Plateau & You et al. (2009) & SO & $1961-2004$ & $\mathrm{~T}$ & A, Seasonal & Yes & $p \leq 0.01$ & - \\
\hline South Korea & Choi et al. (2008b) & SO & $1950-2007$ & $\mathrm{~T}, \mathrm{R}, \mathrm{C}, \mathrm{I}$ & $\mathrm{S}$ & Yes & $p \leq 0.05$ & $\downarrow$ \\
\hline South Korea & Kim et al. (2009) & SO & $1975-2005$ & $\mathrm{~T}, \mathrm{C}, \mathrm{R}, \mathrm{I}$ & A, Seasonal & Yes & $p \leq 0.01$ & - \\
\hline South Korea & Kim and Roh (2010) & SO, RE & 1979-2008 & $\mathrm{T}$ & W & Yes & $?$ & - \\
\hline East Siberia & Mullayarov et al. (2005) & Radionoises & 1979-1994 & Thunderstorm & $\mathrm{W}, \mathrm{S}$ & Yes & $?$ & - \\
\hline SW France & Dessens et al. (2001) & SO & 1889-1999 & Hail & $\mathrm{A}$ & Yes & $p \leq 0.05$ & $\downarrow$ \\
\hline Germany & Bäumer and Vogel (2007) & SO & 1991-2005 & $\mathrm{T}, \mathrm{R}, \mathrm{C}, \mathrm{I}$ & A & Yes & $p \leq 0.01$ & $\downarrow$ \\
\hline Switzerland & Hendricks Franssen (2008) & SO & 1864-2005 & R. S & A & No & - & $\uparrow$ \\
\hline Germany & Quaas et al. (2009) & SO, RS, CS & 2001-2006 & $\mathrm{T}, \mathrm{R}, \mathrm{C}$ & A & No & - & - \\
\hline Switzerland & Barmet et al. (2009) & SO & $1872-2006$ & $\mathrm{R}$ & A & No & - & $\uparrow$ \\
\hline Central/North Europe & Laux and Kunstmann (2008) & SO & $1871-2005$ & $\mathrm{~T}, \mathrm{R}$ & A & Yes & $p \leq 0.01$ & $\uparrow$ \\
\hline Central Europe & Stjern (2011) & SO & 1983-2008 & $\mathrm{T}, \mathrm{R}, \mathrm{C}, \mathrm{P}, \mathrm{W}$ & A, $S$ & No & - & $\uparrow$ \\
\hline Moscow region & Sitnov (2010) & RA & $2000-2009$ & $\mathrm{~T}, \mathrm{H}, \mathrm{P}, \mathrm{W}$ & $\mathrm{S}$ & Yes & $p \leq 0.05$ & $\downarrow$ \\
\hline Moscow region & Sitnov (2011a) & SO, RA & $2000-2008$ & $\mathrm{~T}, \mathrm{R}$ & $\mathrm{S}$ & Yes & $p \leq 0.05$ & $\downarrow$ \\
\hline Moscow region & Sitnov (2011b) & RA & 2004-2009 & $\mathrm{T}, \mathrm{W}, \mathrm{H}, \mathrm{P}$ & $\mathrm{W}, \mathrm{S}$ & Yes & $p \leq 0.05$ & $\downarrow$ \\
\hline Spain & Sanchez-Lorenzo et al. (2008) & SO & 1961-2004 & T, R, C, I, P & $\mathrm{W}$ & Yes & $p \leq 0.05$ & $\downarrow$ \\
\hline Spain & Hendricks Franssen (2009) & SO & 1961-2004 & $\mathrm{P}$ & $\mathrm{W}$ & No & - & $\uparrow$ \\
\hline
\end{tabular}

a Type of data used in the specific studies: surface observations (SO), remote sensing (RS), reanalysis (RE), climate simulations (CS), and radiosonde (RA).

b Variables analysed in the specific studies: temperatures $(\mathrm{T})$, rainfall $(\mathrm{R})$, wind $(\mathrm{W})$, cloud cover $(\mathrm{C})$, insolation $(\mathrm{I})$, humidity $(\mathrm{H})$, and seal level pressure $(\mathrm{P})$,

c Temporal basis used in the specific studies: annual (A), summer (S), and winter (W).

d Reliability of the statistical analysis used in the manuscripts based on a qualitative assessment taking into account the recommendations from Sect. 3: “个”, “-”, and " $\downarrow$ ” indicate high, medium, and low robustness of the statistical analysis, respectively.

2003 there is an increasing interest in the WCs topic, with a large number of studies that claim to have found significant weekly changes in different atmospheric variables. These results have contributed to the general idea of the human impact on weather and climate modification affecting large areas. All these papers are summarised in the following subsections, where they are presented for different regions separately.

\subsection{Studies about WCs from a global or Northern Hemisphere perspective}

The analysis of WCs of different variables at the global scale is still missing at present. The only known analysis has been conducted by Gordon (1994) previously mentioned as one of the pioneer studies. Forster and Solomon (2003) analysed the possible weekend effect, which was defined as the difference between weekend (Saturday-Monday) and weekdays (Wednesday-Friday), for DTR at more than 2000 land surface stations for different countries over the world, mainly including data from North America, Europe, the whole Russia 
(including former Soviet republics), Mongolia, China, Japan, and Australia. Their results showed significant positive differences (which means larger DTR during the weekends as compared to the weekdays) mainly over the south-western and east coast of the US, Mexico, south-western Canada, different locations over Russia, Mongolia, and eastern China. Oppositely, significant negative differences (lower DTR during the weekends) were observed for many stations placed in the central areas of Canada and Japan. Other areas such as Europe and Australia did not show any significant pattern. This implies that the WC is a widespread phenomenon, although it also shows a large-scale pattern. The strong spatial differences in the WCs sign and magnitude are difficult to explain, as for example the absence of significant results over Europe where the anthropogenic emissions and human activities are larger than in other areas that show significant WCs (e.g. Canada, Mongolia, etc.).

Few other studies have analysed different climatic variables over the Northern Hemisphere. For example, Tesouro et al. (2005) detected a WC in the $2 \mathrm{~m}$ air temperature, using NCEP/NCAR reanalysis data, in a window covering $50 \%$ of the Northern Hemisphere centered in the Atlantic Ocean. Their results confirm a significant WC with lower temperatures during the weekend, mainly on Saturday compared to the weekdays, for large parts of the study area (around $75 \%$ of the grid points included in the window). An opposite behaviour with lower (higher) temperatures in the midweeks (weekend) was observed in some areas (around 19\%), mostly located in regions with important snow or ice cover.

More recently Sanchez-Lorenzo et al. (2009), using the same window and NCEP/NCAR reanalysis dataset as in Tesouro et al. (2005), checked the possible WCs in the sea level pressure, but only for the winter period. They found at least 3 atmospheric circulation patterns (among 20 tested) with significant WCs. Each of these 3 patterns shows a different WC, which emphasises the idea of a different large-scale pattern and behaviour in the WCs.

\subsection{Studies about WCs for North America}

As pointed out in Sect. 2.1, Forster and Solomon (2003) detected spatial patterns of significant DTR anomalies across North America. The long time series, starting in mid-20th century, suggested that the significant differences exist during the whole period, despite of some evidence for strong positive anomalies during weekends over the last $20 \mathrm{yr}$ in the south-western USA, while negative signals in the mid-West are largest during the period 1960-1979. On a seasonal basis, the WCs are clearer during the summer, and there are also sectors with an opposite seasonal behaviour; e.g. the Great Lakes region with positive (negative) anomalies during the summer (winter). More recently Kim et al. (2010) revised the possible DTR WCs over North America, using land observational series (1950-2000 period) and NCEP/NCAR reanalysis data (1948-2008) for the summer period. They pro- posed a method based on cyclostationary Empirical Orthogonal Function (EOF) analysis to remove a possible "natural" weekly cycles in the time series data (see Sect. 4.1 for more details). After their attempt to isolate the naturally occurring weekly cycles, they claimed that there was a remaining signal, which is speculated to be anthropogenic, with positive anomalies on weekends in mid-western US (mainly in Colorado and New Mexico) and a strong signal over the Northeast, with the main centre around $40^{\circ} \mathrm{N}$ and $85^{\circ} \mathrm{W}$. Nevertheless, they speculated that the possible natural component in the WC is of the same magnitude, if not stronger, than the anthropogenic component.

Cerveny and Balling (1998), using rainfall remote sensing data (1979-1995 period), analysed the sea area along the eastern coast of the US between the $27.5^{\circ} \mathrm{N}$ and $45.5^{\circ} \mathrm{N}$ and within $5^{\circ}$ longitude from the coastline. They found a general significant increase of rainfall during the week, with a peak on Saturdays and a minimum on Mondays. They also found a significant decrease (increase) during the week in maximum wind speed (pressure), as estimators of cyclonic activity, which seems to be inconsistent with precipitation WC. Finally the results were compared with WCs detected for pollutants such as $\mathrm{CO}$ and $\mathrm{O}_{3}$ measured in Sable Island (43 $57^{\prime}-$ $59^{\circ} 55^{\prime} \mathrm{N}$ ) during the period 1991-1995 (April to October). The measured pollutants showed the highest values during the late week (Thursday-Friday) and lowest in the early week (Sunday-Tuesday). The WC detected in Sable Island could be explained by the downwind advection of pollutants originating from the metropolitan areas at the East-coast, and a corresponding delay of the maximum/minimum values related with the spatial distance between the source of the pollutants and Sable Island. In another paper, the same authors (Cerveny and Balling, 2005) identified significant WCs in the diurnal variations of the tropical cyclone wind speeds for the Atlantic Basin.

Bell and collaborators performed a comprehensive analysis of WC's (Bell et al., 2008, 2009a, b; Rosenfeld and Bell, 2011), which were well-designed to avoid the problem of the "false discovery rate" (FDR) in order to evaluate the field significance as shown by Wilks (2006). They focused on possible WCs during the summertime. In Bell et al. (2008), satellite rainfall data, reanalysis data and observations were analysed (1998-2005 period), and a significant WC was determined for the summertime mean rainfall amount and its intensity over the southeast US. Summertime mean rainfall was found to be higher during the weekdays than in weekends, especially during the afternoons. Wind patterns of reanalysis data and pollutants emission data were found to be in accordance to these results. The authors attribute their results to the hypothesis that anthropogenic air pollution suppresses rainout from shallow clouds and delays the onset of the rainout (see Sect. 4.2 for more details). The detected signal is extended over the nearby Atlantic Ocean, although showing an opposite sign to what happens over land. Bell et al. (2008) suggested that the response over the nearby 
ocean area is a compensatory response of the WCs detected over land. Their results suggest that the suppression of midweek precipitation over the ocean (instead of the invigoration over land) is a dynamical response to the invigorated convection over the land, "as air pumped into the upper troposphere over the continent descends over the surrounding oceanic area, suppressing convection there and reducing its coverage and intensity". Their results are in agreement with the findings of Cerveny and Balling (1998), although this latter study focused the analyses on the whole year (and not on summertime only), used another sensor to estimate rainfall data, and studied an earlier period non-overlapping with the period analyzed by Bell et al. (2008). In later studies, the same team showed more evidences of WCs over the land in south-eastern USA and nearby ocean during the summertime, using different datasets of lightning (Bell et al., 2009a) and storm heights (Bell et al., 2009b), as well as for tornado and hailstorm activity in the entire eastern half of the US (east of $100^{\circ} \mathrm{W}$ ) (Rosenfeld and Bell, 2011). Recently, Tuttle and Carbone (2011) analysed radar-estimated summer rainfall during the period 1996-2007 over the US, and found a significant WC with weekday maxima at many areas in the northeastern quarter of the US and Central Plains after evaluating the field significance in the data (e.g. Wilks, 2006). Equally, an opposite behaviour was found in the southeastern Atlantic coastal zone and northern Florida peninsula, in agreement with other studies (Cerveny and Balling, 1998; Bell et al., 2008). On a regional scale, Svoma and Balling (2009) detected a WC in the winter precipitation frequencies in the Phoenix region (Arizona), with a clear maximum for the weekends (with the peak on Monday) and a minimum on Thursday. Given the regional scale of this study and the fact that these results were specific for the winter period, it is difficult to see if there are some consistencies between these results and other previous findings over large-scales. The results from Svoma and Balling (2009) also suggest that the magnitude of the WC is stronger over the Phoenix urban area, as well as moving eastward (downwind) across the region. Thus, there are evidences of a possible human activity influencing the winter precipitation, possibly by means of the suppression of rainfall due to a weekly fluctuation of the anthropogenic aerosols emissions (Shutters and Balling, 2006). Lacke et al. (2009) analysed the weekly changes in the precipitation for the Atlanta region, showing a general increase of both rainfall and $\mathrm{PM}_{2.5}$ during the mid-week, with a peak on Thursday. They found an opposite weekly pattern compared to the results of Svoma and Balling (2009) in Arizona, suggesting an enhanced precipitation due to the increase in anthropogenic aerosols. Their analysis is based on summer data during the 2003-2004 period and without a control of the FDR, which limits their conclusions. On the other hand, their results are in agreement to the results of Bell et al. (2008, 2009a, b) in terms of enhanced convective precipitation in the south-eastern US during weekdays.
Several papers have been published pointing to the lack of WCs. Grant et al. (2005) did not find any significant weekly differences for DTR for Mount Washington (above the boundary layer) in the north-eastern US. This result is consistent with the findings in Forster and Solomon (2003), which showed no significant weekly DTR cycle in this area. DeLisi et al. (2001) did not find any statistically significant weekly signal for precipitation along the northeast corridor of the US. Due to the controversy and some disagreement in the literature, Schultz et al. (2007) analysed 219 rainfall series from different meteorological stations placed across the whole US using data from the period 1951-1992. The results of their study indicate that neither the occurrence nor the amount of precipitation differs significantly between the days of the week, both for the full data set and for each station on annual basis. They also claimed to find a non-significant weekly signal during the summer period, in contrast to the results reported by Bell et al. (2008), which was unpublished at the time Schultz et al. (2007) submitted their paper, for the south-eastern US. Bell and Rosenfeld (2008) published a comment on the paper of Schultz et al. (2007) indicating that the two studies by Bell et al. (2008) and Schultz et al. (2007) used different time periods and are thus not comparable, as well as the former was designed to study weekly cycles in large-scales averages instead of single sites as in the latter one. Equally, Bell and Rosenfeld (2008) suggested that "a more focused approach - if guided by physical theory can extract far more useful information from a dataset than generic statistical searches".

\subsection{Studies about WCs for Asia}

Forster and Salomon (2003) found significant weekend effects in DTR for China and Japan for a $20 \mathrm{yr}$ period (1980-1999). Regarding Japan exclusively, Fujibe (2010) detected statistically significant weekday-weekend temperature anomaly differences at urban sites in Japan with large population densities, but not significant differences at more rural sites.

For China, analyses of WCs more detailed than in the work by Forster and Solomon (2003) have been published during the last years. Gong et al. (2006) analysed different meteorological variables from 1979 to 2000 in East China. They claimed that for some areas wintertime DTR anomalies tend to be significantly larger for weekend days (compared to weekdays), in association with increased maximum temperature and total irradiance but decreased relative humidity. Summertime DTR anomalies display a much stronger negative weekend effect (i.e. smaller DTR in weekend days), in association with decreased maximum temperature and decreased total solar irradiance but increased relative humidity and a greater number of rainy days. The authors suggested that the weekly differences would be physically related to the direct and indirect effect of anthropogenic aerosols. One year later, Gong et al. (2007) reported important features 
(magnitude and phase) of the WCs of aerosol concentration and the covariations in meteorological conditions in major urban regions over east China for the period 2001-2006. The $\mathrm{PM}_{10}$ concentrations show significant WCs with the largest (smallest) values around midweek (weekend). Consistently to the $\mathrm{PM}_{10}$ concentrations, the meteorological variables show significant WCs. The wind speed in the lower troposphere is relatively low in the early part of the week and increases after about Wednesday. At the same time, the air temperature anomalies in low levels are positive and then become negative in the later part of the week. The authors hypothesize that the changes in the atmospheric circulation may be triggered by the accumulation of $\mathrm{PM}_{10}$ through diabatic heating of the lower troposphere. Similarly, Choi et al. (2008a) studied the region-dependent anthropogenic weekly variation of air pollutants and its relationship with the meteorological conditions over China for the summers of 2001-2005. The mean $\mathrm{PM}_{10}$ concentrations have a regional distribution that depends on the population and geographical setting of a city, its prevailing climatic conditions, and the type and degree of human activities. Their results confirmed the presence of interactions between $\mathrm{PM}_{10}$ and meteorological conditions in the boundary layer. Furthermore, they suggested a possible link of cloud formation and $\mathrm{PM}_{10}$ concentration on weekly scale. Ho et al. (2009) studied the weekend-effect for DTR, relative humidity, cloud cover, and light rain frequency over north-eastern China for the summers between 1980 and 2005. They found that the signals are not stationary over time, resulting from a shift in the phases. The authors speculated that the long-term change of the weekend effect is associated with a decrease in the relative humidity over the region, most likely induced by regional warming. You et al. (2009) examined the weekend effect of DTR in the eastern and central Tibetan Plateau during 1961-2004 at about 70 stations with elevations above $2000 \mathrm{~m}$ above sea level. Negative (positive) anomalies were found for autumn/summer (winter/spring). Principal Component Analysis (PCA) was performed to group the stations into regions with similar weekend effect. As the WCs cannot be explained by microclimate alone, the authors suggested an interaction between local emission of anthropogenic aerosols and transport by atmospheric circulation.

For South Korea, Choi et al. (2008b) examined daily cloudiness, insolation, DTR, relative humidity, and precipitation for 11 meteorological stations from 1950 to 2007 . They found that for summers during the years 1960-1980, the midweek cloudiness is greater than the weekend cloudiness. After 1980, the weekend effect has become again as small as before 1960. Meteorological variables such as insolation, DTR, relative humidity, and light rain frequencies show weekend effects which are consistent with the cloudiness WC. Thus, the cloudiness weekly variation in South Korea is assumed to be associated with aerosol-cloud interactions that depend on aerosol types and geographical and meteorological conditions. Also for South Korea, Kim et al. (2009) identified weekly periodicities in the daily Tmin, DTR, cloud fraction, and insolation, although the cycles for these variables have different phases and magnitudes. It is found that weekly periodicities are enhanced especially in autumn, more than 2-3 times greater than those of the annual mean. They speculated that the WCs are most likely driven by changes in cloud fraction, possibly through aerosol-cloud interactions induced by aerosol concentrations which differ between working weekdays and Sunday. A last paper which focused on the WCs topic in Seoul (South Korea), was published by Kim and Roh (2010). They extracted the first three principal modes of wintertime surface temperature variability in Seoul, for the 1979-2008 period, using observed records and NCEP reanalysis data via cyclostationary EOF analysis as Kim et al. (2010). They found a near-7-day oscillation pattern which they claimed to be the result of "natural" weekly cycles (see Sect. 4.1 for more details), although the robustness of the method needs further scrutiny as has been previously pointed out.

Finally, Mullayarov et al. (2005) observed a WC in thunderstorm activity variations in East Siberia which they suggested to be related to the industrial activities.

\subsection{Studies about WCs for Europe}

Ashworth (1929) claimed, for the first time, a possible decrease of rainfall on Sundays in some English cities. He detected up to $13 \%$ less rainfall on Sunday in Rochdale (near Manchester), with a more clear signal during the winter season, and speculated that the industrial emissions of smoke and hot gases from mill chimneys are responsible for this effect. His studies were confined to urban areas, and for this reason he might be considered as a pioneer in "urban" WCs of meteorological variables over cities. Interestingly, Ashworth also can be considered a precursor of the idea of largescale WCs, as he claimed (Ashworth, 1929; p. 347): "if it be admitted that this emission of smoke and hot gases from factory chimneys can influence rainfall, then it may be asked how far does this influence extend? Or is it narrowly confined to the immediate vicinity of factories?"

Dessens et al. (2001) found an increase of the kinetic energy per hail fall event of about two times on weekends, as compared with weekdays, in an inland area of south-western France. In fact, in their 11-yr of data they also confirmed a decrease in the hailstone size during the weekdays, being the WCs in the regional atmospheric pollution the most plausible explanation for these evidences in their hail data set.

Forster and Solomon (2003) analysed also some European stations. Their results confirmed a non-significant signal in the major part of the analysed sites, pointing out that this finding can be considered "interesting and perhaps surprising" as they found clear significant DTR weekend effect over other developed/polluted areas in the world.

Bäumer and Vogel (2007) claimed for statistically significant WCs in different meteorological variables on annual 
basis over Germany. They used 12 meteorological stations, with data comprising the period 1991-2005. Their analyses, which are only based on applying a one-tailed t-test to the days with the larger anomalies in their day-of-the-week averages (see Sect. 3 for more details about the inappropriateness of this approach), showed a general tendency towards higher temperatures and reduced cloudiness and rainfall for the first half of the week as compared with the second half, with a maximum (minimum) centred on Tuesday or Wednesday (Saturday). They suggested that these periodicities are non-local, as they are also visible in remote rural stations (e.g. Mount Zugspitze, 2960 m a.s.l. in the Alps), and consequently cannot be explained only by local pollution or local heat emissions. The publication of Bäumer and Vogel (2007), together with a second paper focusing on WCs of aerosol optical thickness over Central Europe (Bäumer et al., 2008, see Sect. 4.2.1 for more details), was followed by an important increase in the interest for the large-scale WCs topic in Europe. In a comment, Hendricks Franssen (2008) doubted the statistical significance of the WCs claimed by Bäumer and Vogel (2007). He analyzed rainfall and sunshine data from two stations in Switzerland (Zürich and Lugano) covering the 1864-2005 period with help of a Monte Carlo bootstrapping method and showed that even stronger WCs than those observed in Germany could be obtained by chance. Overall, Hendricks Franssen (2008) found that these two Swiss stations did not show any significant WC for the investigated period. Thus, he questioned whether the results found by Bäumer and Vogel (2007) can be considered significant, and suggested that neglecting "spatial auto-correlation while assessing the statistical significance of the merged time series" could probably explain why Bäumer and Vogel (2008) found significant WCs. In their reply, Bäumer and Vogel (2008) argued that the analysis performed by Hendricks Franssen (2008) for the two Swiss stations does not imply any scientifically sound conclusions for Germany. They also argued that daily precipitation shows a limited spatial auto-correlation.

Laux and Kunstmann (2008) extended the work of Bäumer and Vogel (2007), considering more meteorological stations in Germany, as well as eight more countries over Central and Northern Europe (Denmark, France, Finland, Great Britain, Ireland, Iceland, Norway, and Sweden). They analysed annual rainfall and temperature time series with help of a bootstrapping method using observations partly dating back to 1871. Their results confirm significant WCs in Tmax, Tmin, and DTR over Germany, which are partly in agreement with Bäumer and Vogel's (2007) results. Apart from the results of Bäumer and Vogel (2007), Laux and Kunstmann (2008) found Thursday being the day of the week with the largest positive temperature anomalies. They found a significant weekly signal for temperature in most European countries (except for Finland), but with an unclear pattern in the spatial distribution of the weekly anomalies (see Fig. 2 and Table 1 in Laux and Kunstmann, 2008). In general, tempera- ture anomalies show a positive maximum around midweek days and a minimum on the weekends or Mondays. As the data analysed by Laux and Kunstmann (2008) are for different levels of urbanization and heat emission, it is concluded that the spatial patterns of the weekday differences cannot be explained by local effects exclusively. It is speculated that the atmospheric circulation pattern, possibly triggered by regional accumulation of air pollutants in the lower atmosphere could play a major role. On the other hand, no significant weekly differences are found in the rainfall series, which is in contradiction with the results of Bäumer and Vogel (2007).

Barmet et al. (2009) extended the analysis of Hendricks Franssen (2008). They analysed 17 Swiss meteorological stations for possible WCs in annual rainfall for different periods since 1870 . They also introduced different statistical techniques for significance testing of WCs such as the nonparametric Kruskall-Wallis test, showing how this test produces less spuriously significant results than parametric ttest. In agreement with Hendricks Franssen (2008) they did not find any statistically significant WC for rainfall in any of the analysed periods. One year later Quaas et al. (2009) published a work trying to verify the possible WCs over a large area in Europe using, for the first time to our knowledge, two state-of-art global climate models (GCM). The different GCM simulations are compared against ground-based observations (2001-2006 period) and satellite data (2000 2008 period). Their results showed that neither annual surface temperature ( $T_{\text {mean }}$ and $T_{\max }$ ) nor rainfall show a significant WC linked to the indirect aerosol effect on clouds. They conclude that their “... results suggest that WCs ... cannot readily be attributed to aerosol indirect effects, at least not given the current state of the art as implemented in global climate models".

More recently, Stjern (2011) made another contribution to the study of WCs in Central Europe, as she analysed 30 surface stations in a highly polluted area on the borders between Germany, Poland and Czech Republic. In this study annual and seasonal (winter and summer) series for different meteorological variables (rainfall, cloud cover, temperatures, and surface pressure) were considered for the 1983-2008 period. Stjern (2011) did not find any significant WCs, except in summer cloud cover and light precipitation events, with midweek minimum and larger values for the weekends. In some agreement with these last findings, Sitnov (2010, 2011a, b) found significant WCs during summer in the Moscow region. The author claims that the significant cycles in temperature, pressure, humidity and wind shown for the Moscow region are not just confined to the surface, and also visible in the entire troposphere and stratosphere. Compared with the possible summer WCs found by Stjern (2011) over Central Europe in cloud cover or light rainfall events, the results obtained by Sitnov $(2010,2011 \mathrm{a})$ show an opposite sign in the anomalies, as he detected a general increase (decrease) in the air pressure and humidity during the weekends (central weekdays). 
Concerning Southern Europe, Sanchez-Lorenzo et al. (2008) claimed to find significant winter WCs over Spain for different meteorological variables (temperatures, rainfall, cloud cover, sunshine duration, and sea level pressure) using data for the 1961-2004 period. The results showed a tendency towards positive (negative) anomalies of rainfall, cloud cover (DTR, sunshine duration, and sea level pressure) during the central days of the weekdays, and the opposite anomalies for weekends. As they used series distributed over different geographical areas with different levels of urban influence, they argued that these WCs can hardly be related only to local effects, suggesting a possible link with periodicities in atmospheric circulation over Western Europe. Hendricks Franssen et al. (2009) commented the paper, pointing out some deficiencies in the statistical analysis (mainly linked to neglecting the strong spatial auto-correlation in the statistical analysis). They claimed, on the basis of non-parametric testing, Monte Carlo bootstrap methods and a periodogram analysis, that the WCs of air pressure are not significant over Spain (for more details see Sect. 3). In their reply, Sanchez-Lorenzo et al. (2009) agreed with some of the deficiencies pointed out in the comment, although suggesting that the analysis should be applied for all the meteorological variables (not only air pressure), specially for the ones with low spatial auto-correlation (e.g. rainfall). Anyway, they also showed new evidences of winter WCs in DTR over Spain after the application of more robust statistical analysis by using PCA techniques and the non-parametric Kruskall-Wallis test.

\section{Weekly cycles dilemma: a statistical tale}

We have seen in Sect. 2 and Table 1 that many of the published papers report a significant WC in some of the meteorological variables. Therefore, it could be considered that such WCs are widespread. However, the results should be interpreted with caution and it is not so clear whether meteorological variables show WCs over large spatial scales. Indeed, there are several reasons why significant WCs might be less widespread than it may seem from the above reviewed papers:

1. The occurrence of WCs in meteorological variables is analysed with help of statistical tests, and the common procedure is that a WC is considered to be significant if the $H_{0}$ hypothesis is rejected on the basis of a certain significance level. In several papers (e.g. Bäumer and Vogel, 2007; Sanchez-Lorenzo et al., 2008; Kim et al., 2009) the t-test is applied on averaged time series. The test is applied taking as number of data the total number of observations summed over all-time series. This procedure is only correct if the different time series are independent. However, this is rarely the case because meteorological variables always show some degree of spatial autocorrelation, which results in dependency for time series among stations that are relatively nearby in geographical space. As many studies focus on the analysis of time series from a limited region, like for example a country, statistical dependency between time series becomes an issue. Meteorological variables like air pressure or temperature show a correlation over distances which are typically larger than $1000 \mathrm{~km}$. Neglecting statistical dependency between time series results in an overestimation of the number of independent stations. Hendricks Franssen (2008), Barmet et al. (2009) and Hendricks Franssen et al. (2009) showed that neglecting this statistical dependency might result in confidence intervals around estimates which are much too small and non-significant stochastic fluctuations might be interpreted as significant. The dependency of time series is not an issue if the t-test is applied on individual time series. However, the number of measurements is often too small for a representative analysis for a certain region. The use of the t-test for detecting significance of WCs is problematic for other reasons. Also normality of the observations is assumed, which is not always a reasonable assumption. To what extent this affects the results reported in papers is unclear and has not been the specific subject of research. Equally, most studies that use the t-test are implicitly examining 21 pairs of day-of-the-week averages, and then they perform a posteriori t-test on the pair with the largest differences in the averages. This approach suffers of the effects of the FDR, which should be taken into account to evaluate the significance level of their findings.

2. Also the interpretation of significance testing is often doubtful in scientific papers concerned with a WC in meteorological variables. If an anomaly for a certain weekday is significant at the $95 \%$ level, this implies that there is a chance of 1 out of 20 that this significance is nevertheless an artifact of randomness. An example can be found in the work of Gong et al. (2006). They reported a significant WC (at the $90 \%$ level) of the DTR during winter time at 8 out of 171 stations (i.e. $4.7 \%$ of the stations). One would expect a significant cycle at $10 \%$ of the stations (i.e. 17 stations) just by chance. Therefore, it should be concluded that during winter time there is no evidence for a significant weekly DTR cycle. During summer time the WC is significant for 36 out of 171 stations (i.e. $21 \%$ of the stations). Gong et al. (2006) focus their analysis therefore on significant WCs during summer time. However, does the relatively large number of stations with a significant weekly DTR cycle really imply that this cycle is significant? In fact, the maps that Gong et al. (2006) provide indicate that the stations are not independent, and also in this case spatial autocorrelation between stations has to be taken into account for judging if 36 significant WCs (out of 171 ) is in itself significant. An additional problem in this 
respect is that several authors tend to focus their analysis on a certain season, a certain region and a certain decade. This approach could seriously affect the analysis through the FDR problem as the sites and/or seasons used to examine the significance are selected post hoc. As explained for the article of Gong et al. (2006), it should be considered that WCs are not significant for other seasons of the year or other decades, and repeating statistical significance testing for many different scenarios finally always will result in some significant results. If significant results are only found for a certain season or a certain historical period a scientific reasoning would be desirable to explain why one expects for that season or a specific time period a more pronounced WC than for other seasons or historical time periods. If such a scientific reason cannot be given, it should be taken into account in the analysis of the results that for other time periods and other seasons testing results are not significant.

3. It is also important to realize that tests which did not result in a significant WC were in general not published in the scientific literature, whereas significant WCs are much more likely to have been published. This is well known under the name of "publication bias" in the medical literature. It was found that statistically significant results are three times more likely to be published than papers without such significant results (Dickersin et al., 1987), mainly because the investigator less likely will submit non-significant results to a journal (Easterbrook et al., 1991).

Other authors used some alternative testing procedures with less restrictive assumptions for the analysis of WCs (Hendricks Franssen, 2008; Laux and Kunstmann, 2008; Barmet et al., 2009; Hendricks Franssen et al., 2009; Marani, 2010). Monte Carlo bootstrapping methods can deal with arbitrary probability distributions and dependencies between time series observed at different meteorological stations. For testing the presence of the WC in a time series, which is averaged over several stations, the original time series is randomly resampled. A large number of samples are needed in order to test the significance of a WC. For each of the samples the WC is reconstructed and from the large number of samples the probability density distribution of the anomalies (for each of the weekdays) can be calculated and compared with the observed anomalies. In order to handle well the temporal autocorrelation present in the time series the block size of the sampling window is important to consider. The block size should be large enough to include relevant temporal autocorrelation, but should be different from seven days in order to remove a possible WC from the data. Hendricks Franssen (2008) neglected temporal autocorrelation and used a block size of only one day. Laux and Kunstmann (2008) used in their Monte Carlo bootstrapping procedure a block size of 1-50 days.
Instead of the popular t-test, an alternative for testing the significance of WCs is the Kruskal-Wallis test, which has been used by some authors (Barmet et al., 2009; Hendricks Franssen et al., 2009; Sanchez-Lorenzo et al., 2009; Stjern, 2011). The Kruskal-Wallis test can be applied for testing the whether the mean ranks of the sets are from different populations. It is a non-parametric test which is not restricted to the normality distribution. Therefore, it is in principle more flexible than the t-test. The Kruskal-Wallis test is able to test simultaneously the difference between various groups (like all the weekdays), whereas the t-test is limited to testing the differences between two groups only (Barmet et al., 2009). However, like for the t-test, care has to be taken for the analysis of different time series which show spatial autocorrelation. For the analysis with the Kruskal-Wallis test, the individual time series have to be used as basis for the testing procedure (not the averaged time series from multiple observation locations).

The significance of the WC can also be evaluated by a Fourier analysis (e.g. Barmet et al., 2009; Hendricks Franssen et al., 2009; Quaas et al., 2009). The periodogram should show a clear distinct spectral peak at $1 / 7 \mathrm{~d}^{-1}$. However, significance testing of the spectral peak is not trivial. Therefore, often the periodogram is only used for a somewhat qualitative assessment of the significance of a WC. Monte Carlo bootstrapping or the Kruskal-Wallis test provides a more quantitative framework to test the significance of a WC.

It has proven useful to test the method by investigating hypothetical 6- or 8-day weeks to corroborate the significant results if a 7-day week shows significance, but both 6- and 8 -day weeks do not. On the other hand, there is little confidence in a method which shows significant cycles for 6- or 8-day weeks (Barmet et al., 2009; Quaas et al., 2009), although it is worth noting that testing for cycles at different frequencies should imply an adjustment of the significance test to compensate for the FDR.

Finally, it is important to remind that a null statistical result does not prove the non-existence of a significant WC, as a lack of well-designed statistical test can produce a null result when a better-designed might have revealed a significant one (e.g. see Hasselmann, 1979; Bell, 1986).

Taking into account all the recommendations summarized in this section, we have added a last column in Table 1 with a qualitative indication of the complexity and robustness of the statistical analysis used and described in the different manuscripts. A full assessment of these analyses is, however, beyond the scope of the current manuscript, as currently there is no consensus on how to proceed in order to evaluate the statistical reliability of WCs.

Finally, very recently, Daniel et al. (2012) have highlighted and quantified some of the statistical problems pointed out in this section, so this latter work must be considered an essential reading to complement this review. 


\section{How can we explain large-scale WCs?}

As we have seen, there are still uncertainties about the existence of large-scale WCs, e.g. due to the lack of statistical significance in some studies (e.g. DeLisi et al., 2001; Schultz et al., 2007; Barmet et al., 2009, see Sect. 2 and Table 1), or the low robustness of the statistical tests used in some of the papers reporting significant WCs (see Sect. 3). Anyway, there is an important number of papers claiming for the existence of significant large-scale WCs in meteorological variables (see Sect. 2 and Table 1), most of them suggesting possible causes to explain these periodicities in their data sets. Thus, here we will briefly summarize the main factors suggested until now, mainly focusing our attention on the possible role of the direct and indirect effect of aerosols on climate, which is the main mechanism suggested by the literature as the possible responsible of the WCs. However, we will start mentioning the natural causes that have also been claimed to be related to WCs.

\subsection{Non anthropogenic (or natural) factors}

There is no known natural process generating constant cycles of 7 days during long time periods. Anyway, it is interesting to point out that Forster and Solomon (2003) wrote that Cerveny and Balling (1999) "suggested that lunar effects project onto the weekly", as possible cause of the WCs detected on different meteorological variables. It is true that Cerveny and Balling (1999), among others, claimed in different studies for a significant influence of the different lunar phases (with a complete cycle of 29.53 days) on the earth's climate. However, a statement about a possible link between the WCs and lunar phases cannot be found in Cerveny and Balling (1999), neither in some of their other references about this subject (R. S. Cerveny, personal communication, 2011).

On the other hand, Forster and Solomon (2003) suggested that weekend differences might be related to a "nongeophysical anthropogenic cause could arise from weekend differences in recording practices at individual stations". They argued that this might be an important issue when few isolated stations are considered which are not well-maintained, but that it seemed a very unlikely explanation for the cycles found in the major part of the current studies, as in these studies mainly first-order and homogeneous stations, or automatically operated measurements such as from satellites, were used. Forster and Solomon (2003) briefly cited as a possible cause (but not plausible for their analysis) the random projection of the synoptic scale low pressure systems, which typically have a life time around one week. Although suggested as a cause, to our knowledge there was not too much attention to this option in the subsequent studies. Only recently, Kim and collaborators pointed out a possible impact of the natural atmospheric circulation on the WCs. In their study Kim and Roh (2010) determined the first three principal modes of wintertime surface temperature variability in
Seoul (South Korea) from the 1979-2008 period using a cyclostationary EOF analysis - CSEOF - (a type of EOF analysis that takes into account the periodically time-dependent covariance statistics). They found a second and third CSEOF mode with around $\sim 7-8$ days oscillations, claiming that the eastward propagation of the Rossby waves was the main physical mechanisms explaining this finding. Similar conclusions were also reached in a second work (Kim et al., 2010) analysing the DTR and other meteorological variables over North America. In this study, Kim et al. (2010) proposed to define a "natural" WC, linked to a Rossby waves projection in the data, as opposed to the "anthropogenic" WCs, being both components sometimes present in the climate data. Thus, they found a stronger natural component in North America, showing a different spatial pattern in the WCs after removing this component and only keeping the anthropogenic one. It is important to notice that although they found this spatial change in the WCs signal, a remaining significant anthropogenic cycle was still visible. Consequently Kim et al. (2010) did not reject the possibility of WCs linked to anthropogenic activity. In fact, they mainly suggested the necessity to a more careful scrutiny of the data previous to analysis. Future works are needed in order to confirm their hypothesis and the suitability of the method. On the other hand, Bell et al. (2009a, Supplementary Material) did not find any evidence of weekly cycles in the synoptic-scale variability over North America.

Thus, currently there are no conclusive evidences of natural (or at least non-anthropogenic) factors that can explain the significant WCs signal found in different areas across the world.

\subsection{Anthropogenic factors}

Although Forster and Solomon (2003) suggested other anthropogenic factors for a possible explanation in the WCs such as changes in agricultural practices as flooding or ploughing, Simmonds and Keay (1997) concluded that any WC linked to an anthropogenic activity should be due to human heat generation or the release of atmospheric pollution.

Gordon (1994) hypothesised "that a human-induced heat signal is present" in order to explain the weekly differences in the temperatures over the Northern Hemisphere. The main idea is that during the weekdays there is a greater generation of heat when compared with the weekends, with a consequent increase of the temperatures. This increase in the temperature during the weekdays can enhance boundary layer convection, e.g. as suggested by Simmonds and Keay (1997) in order to explain the rainfall increase in Melbourne during the weekdays. On the other hand, other studies (e.g. Kaufmann et al., 2007) also suggested a negative feedback of urbanization on large scale rainfall, invoking other mechanisms which, however, are not expected to show weekly periodicities (e.g. changes in vegetation, roughness, albedo, etc.). 
Although Simmonds and Keay (1997) found the connection between urban WCs and the anthropogenic heat emissions in Melbourne, in line with the hypothesis of Gordon (1994), afterwards this mechanism has been not considered to be the main factor controlling the large-scale WCs. Studies published later rejected this hypothesis because nonsignificant differences in the WCs between stations located in urban and rural areas were found. Also Bell et al. (2008) stated that the heat produced by human activities "is too small to affect circulation" in order to produce large-scale WCs.

The impact of the anthropogenic pollution is a second possible anthropogenic cause to explain the WCs. In fact, the possible effect of the urban pollution on the weekly modification of the rainfall was a long time ago suggested by Ashworth (1929), and quickly considered as a possible factor also controlling the large-scale WCs (Lenschow, 1994). Cerveny and Balling (1998) argued about the possible effect of the pollution on the WCs found for the coastal Atlantic near North America. Afterwards, the major part of the studies reporting significant WCs claimed that pollution was the factor controlling the significant large-scale WCs. In fact, the direct and, especially, indirect effects of anthropogenic aerosols have been suggested as the main cause for WC's, with some studies showing evidences of this connection, i.e. mainly linked to the indirect effects of aerosols including the thermodynamic effects (e.g. Bell et al. 2008, Rosenfeld and Bell, 2011). Thus, very often the analysis of possible WCs in meteorological variables is accompanied by an analysis of air pollution and anthropogenic aerosols.

Due to the ongoing interest in the possible aerosol effect in the large-scale WCs of different meteorological variables, in the next subsections we will briefly summarize the main studies showing WCs of different pollution variables and anthropogenic aerosols, especially for the ones focusing on large-scales (Sect. 4.2.1). Afterwards, we will briefly summarize the main direct and indirect aerosol effects (Sect. 4.2.2) in order to give an idea about the possible physical and chemical mechanisms maybe involved in the large-scale WCs.

\subsubsection{Evidences of WCs in pollution and anthropogenic aerosols}

The idea of investigating local scale pollution WCs is quite old, dating back to the previous cited work of Ashworth (1929). Latterly, Haagen-Smit and Brunelle (1958) initiated the investigation of the WC of photochemical parameters, while the $\mathrm{WC}$ of photochemical pollutants, ozone, primary pollutants such as nitrogen oxides $\left(\mathrm{NO}_{\mathrm{x}}\right)$, carbon monoxide (CO) and aerosols was studied in a significant number of papers from mid 70s (e.g. Cleveland et al., 1974; Elkus and Wilson, 1977), mainly for urban centres in the US. Thus, many studies, particularly in America and Europe, from the late 70s until today, suggested that ozone concentra- tions are generally higher during the weekend when the emissions of $\mathrm{NO}_{\mathrm{x}}$ and volatile organic compounds (VOCs) are lower due to a decreased use of transport facilities in urban areas, while ozone may minimize in the weekends in rural areas or areas with high biogenic VOC emissions (see Heuss et al., 2003 for a review).

Equally, during the recent years the ground-level aerosol concentration differences during the week have been examined for sites situated in Central and North America (e.g. Murphy et al., 2008), Europe (e.g. Barmet et al., 2009) and Asia (e.g. Gong et al., 2007; Choi et al., 2008a; Kim et al., 2009) suggesting lower values during weekends and higher values during workdays, which can be attributed to decreased industrial activity and traffic during weekends in urban and industrialised regions, as well as the ban on heavy-duty vehicle traffic on Sundays in some areas. Similarly, Murphy et al. (2008), used measurements from both urban and rural stations around the US arguing that the aerosol concentration WC cannot be attributed exclusively to local sources.

Aerosols may potentially have a substantial contribution to the triggering of the observed WC of meteorological and climatic variables through their direct and indirect effects (see Sect. 4.2.2 for more details). This clarifies how important is the detection and quantification of the WCs in tropospheric (not only measured on ground surface level) aerosol load from both ground and satellite-based observations. WCs of the aerosol optical depth (AOD) from the Aerosol Robotic Network (AERONET) were reported by Jin et al. (2005) over New York, and by Bäumer et al. (2008) in Central Europe. Xia et al. (2008) investigated the WC of $\mathrm{AOD}_{440 \mathrm{~nm}}$ over 169 AERONET stations around the world finding significant midweek maxima and weekend minima over the US and Central Europe, with the differences between weekend and midweek being greater for the urban sites than for rural sites. Results for selected other regions (e.g. South and East Europe, Africa, South America, China, and the region of Middle East) show a less pronounced WC. In conjunction with the ground-based observations, Xia et al. (2008) initiated the investigation of aerosol large scale WCs from space using AOD $550 \mathrm{~nm}$ measurements from MODIS TERRA (March 2000-May 2007 period). The remote sensing data were used to complement the ground-based data, and to confirm if the WCs in AOD found in the AERONET stations was a phenomenon of a larger-scale. The spatial analysis revealed a clear WC over Central Europe and the East coast of US with maximum-minimum day difference of $\sim 8 \%$ compared to the weekly mean in both cases. However, the day of maximum and minimum $\mathrm{AOD}_{550 \mathrm{~nm}}$ differed for the two regions; Thursday and Sunday for the US East coast, while for Central Europe there are no large differences during midweek with a striking minimum on Monday. Signs of an opposite WC were observed over regions in China (Yangtze delta region) and India. The Sunday maximum observed for this region in Eastern China is in contrast with the clear summertime $\mathrm{PM}_{10}$ weekend minima reported by Gong et al. (2007). 
However, the first study that observed pollution WCs from space focused on tropospheric $\mathrm{NO}_{2}$ (Beirle et al., 2003). Satellite measurements from the Global Ozone Monitoring Experiment (GOME) aboard ERS-2 revealed a clear Sunday minimum with reduced $\mathrm{NO}_{2}$ tropospheric columns compared to the working-day levels over the US, Europe and Japan. Beirle et al. (2003) found no WC over China, with a clear Friday (Saturday) minimum in the Middle East (Israel), indicative of the cultural and religious differences in these regions. Hayn et al. (2009) suggested on the basis of GOME measurements that the variability of tropospheric $\mathrm{NO}_{2}$ is only significant for densely settled and industrialised regions around the globe. As far as Europe is concerned, they observed a clear Sunday minimum over the whole Central Europe, a large part of Spain and Italy, with the minimum being shifted to the beginning of the week for regions of Eastern Europe due to synoptic $\mathrm{NO}_{2}$ transport by the dominating westerly winds. Supportive of the regional character of the $\mathrm{NO}_{2}$ WC over Central Europe are the results of Gilge et al. (2010), who found $\mathrm{WCs}$ of $\mathrm{NO}_{2}$ concentration even at mountainous stations in Germany (Hohenpeissenberg: $985 \mathrm{~m}$ ) and Switzerland (Jungfraujoch: $3580 \mathrm{~m}$ ). Also Stjern (2011) found a clear $\mathrm{NO}_{2} \mathrm{WC}$ for four rural stations situated around the highly industrialised Black Triangle region (borders of Germany, Poland and Czech Republic).

Quaas et al. (2009), following a different approach used spatially averaged satellite $\mathrm{AOD}_{550 \mathrm{~nm}}$ observations from both MODIS TERRA (March 2000-March 2008) and MODIS AQUA (July 2002-July 2007) for a region covering a large part of Europe. By modifying the climatological emissions of anthropogenic aerosols and aerosol precursors in two global climate models (HadGEM2 and ECHAM5) so that the weekend emissions are about one third lower than the weekday emissions they observed a statistically significant WC in aerosols which is not observed when the standard emissions are used. This shows that the existence of a WC in the emissions could indeed lead to a WC of the aerosol load in the troposphere. However, despite the fact that the observed Monday minimum from satellite is relatively well captured by the model simulations, the corresponding maximum-minimum day difference calculated from the satellite data is much lower than for the model calculations.

Georgoulias and Kourtidis (2011) presented a comprehensive spatiotemporal analysis of the aerosol WC over the European region on the basis of MODIS TERRA (February 2000-February 2009) and MODIS AQUA (July 2002December 2008) AOD $_{550 \mathrm{~nm}}$ measurements. Their results revealed three major WC plumes, a strong positive (higher values during midweek) WC plume over central Europe and a strong negative (higher values during weekend) WC plume over the Iberian Peninsula and the north-eastern Europe. The seasonal analysis showed that the annual WC pattern over Europe is driven by the summer weekly pattern. The use of a Fourier-based spectral analysis and a red noise fit indicated the existence of a statistically significant 7-day cycle over central Europe and the Iberian Peninsula. The MODIS aerosol weekly patterns were studied in conjunction with NCEP/NCAR reanalysis wind speed and direction data, showing that the seasonal WC plumes over regions situated in the eastern Europe and the Mediterranean Sea could be attributed to the westerly transport of continental aerosols from the dominating synoptic wind patterns which is in agreement with the findings of Hayn et al. (2009) for tropospheric $\mathrm{NO}_{2}$. The same was also observed at a smaller scale within the region of Central Europe by Georgoulias and Kourtidis (2012) using high resolution level-2 MODIS TERRA data.

On the other hand, non-significant WCs have been observed in the number of cloud condensation nuclei (CCN) measured at several background stations over Europe (Asmi et al., 2011; Asmi, 2012). Further research is needed in order to reconcile these results with the observed WCs in the aerosol mass and optical properties previously reported over Europe.

\subsubsection{Brief summary of direct and indirect aerosol effects}

Large-scale WCs due to anthropogenic emissions of gases or particles can be expected to be significant only if these species are short-lived, i.e. have lifetimes of much less than one week. It is thus expected that no large-scale effects of long-lived greenhouse gases such as $\mathrm{CO}_{2}$ can be reflected in WCs. As discussed above (see Sect. 4.2.1), WCs in aerosols have been observed, consistent with aerosol lifetimes of a few days. It is interesting to note in this context that WCs in aerosol precursor gases, and other short-lived reactant gases, are much more pronounced than WCs in columnconcentrations of optically active aerosol particles, measured as AOD.

Aerosols impact atmospheric processes in different ways, which can be summarised as follows:

1. A "direct" effect on radiation exists: Aerosol particles scatter and absorb solar (and also, but to a much lesser extent, terrestrial) radiation (Ångström, 1929; Charlson et al., 1992). Variability in clear-sky solar radiation is mainly controlled by variability in water vapour and aerosol concentrations. AOD is the aerosol-related quantity best suited to characterise its radiative effect. At the urban scale, Cleveland et al. (1974) found a consistent weekly cycle in surface solar irradiance. Gong et al. (2006) found a weekly cycle in surface solar irradiance over China consistent with the expected aerosol direct effect in winter, but not in summer. Quaas et al. (2009) did not find any significant signal in clear-sky radiation as measured by TERRA and AQUA CERES satellite instruments over Europe.

2. Aerosols also exert so-called "indirect" effects (e.g. see a comprehensive review in Lohmann and Feichter, 2005): the subset of anthropogenic aerosols serving 
Table 2. Weekly cycle expected for selected variables in relation to the different hypothesised aerosol effects (see also Lohmann and Feichter, 2005). "-" indicates an expected reduction on weekends, “+", an expected increase, "o" a neutral effect. The "*”" symbol indicate a relatively high level of scientific understanding.

\begin{tabular}{|c|c|c|c|c|c|}
\hline Aerosol effect & Cloudiness & $\begin{array}{l}\text { Surface solar } \\
\text { radiation }\end{array}$ & $\begin{array}{c}\text { Surface } \\
\text { temperature }\end{array}$ & $\begin{array}{c}\text { Diurnal } \\
\text { temperature range }\end{array}$ & Precipitation \\
\hline Direct effect & $\mathrm{o}^{*}$ & + & $+^{*}$ & $+^{*}$ & $\mathrm{o}^{*}$ \\
\hline Cloud albedo effect & $\mathrm{o}^{*}$ & $+^{*}$ & $+^{*}$ & $+^{*}$ & $\mathrm{o}^{*}$ \\
\hline Cloud lifetime effect & - & + & + & + & + \\
\hline Glaciation effect & + & - & - & - & - \\
\hline Thermodynamic effect ${ }^{1}$ & - & o & o & o & - \\
\hline Semi-direct effect & + & - & - & - & o \\
\hline Feedback from surface cooling & + & o & o & o & + \\
\hline
\end{tabular}

1 The thermodynamic effect might act on cloudiness and subsequently surface solar radiation and temperature via an increase in cirrus cloud cover.

as cloud condensation and ice nuclei modifies cloud droplet and ice crystal number concentrations and size distributions. The immediate effect of such a perturbation of the CCN number concentration on an otherwise unperturbed cloud, is to enhance cloud droplet number concentrations (CDNC), and ice crystal number concentrations in cold clouds, and thus the overall scattering cross section. This enhances cloud albedo (Twomey, 1974) and is also called "first indirect effect" in the literature. Since cloud particle size distributions are altered by anthropogenic $\mathrm{CCN}$, further effects can be expected. It has been hypothesised for liquid-water clouds that with droplet size spectra of generally reduced size, precipitation formation is delayed, enhancing cloud lifetime (Albrecht, 1989). This also implies on average enhanced cloud fraction, larger cloud geometrical thickness and liquid water path (Pincus and Baker, 1994), and subsequently a larger cloud radiative effect. If anthropogenic aerosols are efficient as ice nuclei, a cloud which in unperturbed state would remain liquid may glaciate (Lohmann, 2002) and precipitate more efficiently. In a convective cloud, if precipitation is reduced for liquid-water clouds, more liquid water may reach the freezing level, and freezing is delayed to higher altitudes, the so-called thermodynamic effect or convective invigoration effect (Koren et al., 2005). Such an effect would lead to deeper clouds, and more intense precipitation, although Rosenfeld et al. (2008) pointed out that effects of aerosols might be not linear on storm invigoration. There is a large variety of processes "buffering" such aerosol effects on clouds (Stevens and Feingold, 2009), such as a larger evaporation rate of smaller droplets (Small et al., 2009), or increased droplet spectrum dispersion (Liu and Daum, 2002). If anthropogenic aerosols are strongly absorbing sunlight, they may alter the thermodynamic structure of the troposphere. In particular, as has been hypothesised by invoking the "semi-direct effect", local heating may lead to evaporation of clouds (Ackerman et al., 2000). Finally, as a feedback, the effects of aerosols on surface radiation, and subsequent surface cooling, may lead to a reduction in cloudiness (Rosenfeld et al., 2008).

Taking into account these direct and indirect effects, Table 2 summarises the expected (hypothesised) impacts of the various aerosol effects on the WCs of a selection of observable meteorological variables.

\section{Further research}

A general finding is that WCs in meteorological variables are in general weak at small scales (i.e. at individual sites), because tests often give non-significant or contradictory results. It is therefore important to test the existence of WCs with help of a large amount of experimental data. However, as WCs probably show spatial and even temporal variability related with atmospheric dynamics, as suggested by some authors (Laux and Kunstmann, 2008; Sanchez-Lorenzo et al., 2009), it is important to have many measurements in a relatively limited area. Information from precipitation radar could also be interesting in this context, as has been recently shown by Tuttle and Carbone (2011). Many data in a limited area also means that spatial autocorrelation is very significant and the effective sample size much smaller than the number of stations. However, for precipitation there is still some potential to explore datasets of regions with a very dense network of rain gauges, as well as its shows a weaker spatial autocorrelation than other meteorological variables. Nevertheless, it is crucial to take into account in the analysis that the correlation distances of daily series can be much smaller than the correlation distances for data on weekly time scales, so that the number of effectively independent spatial samples for statistical searches for weekly cycles may be substantially smaller than the number of spatial samples. For such regional studies that consider measurement data from several observation points, it is important that statistical testing is done 
taking into account the effects of the FDR, as well as the spatial and temporal autocorrelation in the data.

Although there is still some potential for regional studies (i.e. specific countries or regions within a continent), we believe that the main focus should lay on larger scales studies (i.e. continental or global scales) that will allow to get an overview of the WC as function of the location in space. This will give insights in the relation between the WC and atmospheric dynamics. If the significance of WCs is estimated for individual grid points, testing is more trivial using for instance the Kruskal-Wallis non-parametric test. It is, however, important to realize, that we expect significant outcomes at some grid points (depending on the chosen p-value) just by the random character of the variable under study. Due to spatial autocorrelation, the locations with significant WCs will also tend to cluster, which should not be confounded with a regionally significant cycle. Therefore it is important to extend the study for large spatial areas and to verify that for an "unexpectedly" large number of grid points a significant WC would be found, which will really support the existence of large-scale WCs. In Bell et al. (2009a, Sect. 2 in the Supplementary Material) there is a clear example of this approach in order to differentiate between "real" weekly cycles and noise in a gridded dataset. They compared at different grid resolutions the number of grid points significant at different levels with the expected number.

For the future it is a major task to better understand the mechanisms that generate possibly weekly cycles. It is therefore important to compare the large-scale patterns of WCs which are determined with atmospheric model calculations. The work by Quaas et al. (2009) is an example of such an approach that can be exploited further, analysing several possible mechanisms for understanding the WC. Equally, in order to attribute a weekly cycle identified for one variable to a specific aerosol effect, it is recommended to select specific aerosol-cloud regimes: the sensitivity of clouds and precipitation to changes in the aerosol concentration depends upon the specific atmospheric conditions (Stevens and Feingold, 2009). Equally, there is a need of a development of the modelling on the scale of individual storms (mesoscale modelling) and improvement of the parameterizations of the effect aerosols on cloud dynamics and microphysics. Nevertheless, it must be noted that current state of the art GCM lack of a good representation of the indirect aerosol effects (e.g. Solomon et al., 2007).

\section{Conclusions}

In this paper we have reviewed the studies reporting significant and non-significant WCs in different meteorological variables over large-scales for different regions around the world, highlighting the main weaknesses in the statistical analyses commonly used in the WCs studies, and summaris- ing the possible physical mechanisms suggested to explain the reported significant WCs.

Regarding the reported significant large-scale WCs, there is not a consistent spatial pattern in the results. In fact, the different methodologies, meteorological variables, and data periods used for the analyses make it difficult to conclude that the large-scale WCs are real, or at least easily detectable in climate series. Consequently, if WCs exist in the climate, they are difficult to discern from natural climate variability, and may be limited to specific regions and seasons (or atmospheric regimes) where the anthropogenic emissions/activities can interact with the atmospheric processes and modify the weather conditions at least over mesoscale areas.

Nevertheless, an existence of significant WCs over North America seems plausible, especially in the south-eastern of the US, as has been reported by different authors (Cerveny and Balling, 1998; Bell et al., 2008, 2009a, b; Rosenfeld and Bell, 2011). Equally, for Asia a large amount of evidence has been published recently pointing out the existence of significant WCs, especially in eastern China, for thermometric variables as a possible response to the temperature and pollution increase in this region during the last decades. Nevertheless, some concerns remain regarding the statistical analysis used in some of these studies: for example, some of them have not taken into account the FDR (e.g. Gong et al., 2006; Choi et al., 2008b; Ho et al., 2009). On the other hand, even more uncertainties exist in Europe as there is no general consensus about the reliability of studies suggesting significant WCs (Bäumer and Vogel, 2007; Sanchez-Lorenzo et al., 2008), as well as there is a greater proportion of studies rejecting the existence of significant WCs. A possible WC in temperature is still likely, as there are significant results for different European countries (e.g. Laux and Kunstmann, 2008; SanchezLorenzo et al., 2009). Although there is no concurrent signal in the WC, it is still important to see whether they are dominantly of a certain sign for a given weekday, and how the spatial patterns can be explained.

On the other hand, the assessment of the statistical significance of the WC faces a number of challenges. These need to be taken into account when the analyses are applied to climate data sets in search of WCs. The major weaknesses in the studies focusing on the WCs topic are linked to (1) neglecting spatial autocorrelation of the data, which if considered will reduce the number of independent series and the degrees of freedom; (2) the need of a better design of the methods in order to detect weekly cycles in large-scale averages; (3) the assumption of the normality in the series, which it is not always present in the climate data, especially when dealing with daily resolution; (4) the necessity of correcting the significance testing for the effects of the FDR problem if the analysis are performed on site by site or season by season basis without specifying choices a priori; and (5) the publication bias towards papers reporting significant results, which 
are more likely to be published than papers showing nonsignificant WCs.

Finally, a summary of the possible causes for the WCs is listed, and the direct and indirect aerosol effects are the most plausible candidates to explain large-scale atmospheric changes in weekly time resolution. The direct and indirect aerosol effects are possible causes for large scale WCs because a large scale WC in the anthropogenic aerosol emission is found. Moreover, the aerosols' effects have a clear impact on the energy balance, and especially on precipitation processes and clouds. More research is needed on this topic, especially in order to improve the statistical methods and analysis of spatial and temporal patterns of the WCs. Additionally it is necessary to identify, understand and quantify the physical mechanisms beyond these atmospheric changes. This will yield a better understanding of the anthropogenic perturbations of the Earth's climate system, and especially the impact of the aerosol effects on the radiative balance.

Acknowledgements. This work was partially supported by the Spanish Ministry of Science and Innovation project NUCLIERSOL (CGL2010-18546). Arturo Sanchez-Lorenzo was granted by a postdoctoral position funded by the government of Catalonia (2009 BP-A 00035). Finally, we would like to thank an anonymous reviewer, and in particular the very thorough and constructive review of Thomas L. Bell.

Edited by: F. Yu

\section{References}

Ackerman, A. S., Toon, O. B., Stevens, D. E., Heymsfield, A. J., Ramanathan, V., and Welton, E. J.: Reduction of tropical cloudiness by soot, Science, 288, 1042-1047, 2000.

Albrecht, B. A.: Aerosols, cloud microphysics, and fractional cloudiness, Science, 245, 1227-1230, 1989.

Ångström, A. K.: On the atmospheric transmission of Sun radiation and on dust in the air, Geogr. Ann., 11, 156-166, 1929.

Arnfield, A. J.: Two decades of urban climate research: a review of turbulence, exchanges of energy and water, and the urban heat island, Int. J. Climatol., 23, 1-26, 2003.

Ashworth, J. R.: The influence of smoke and hot gases from factory chimneys on rainfall, Q. J. Roy. Meteor. Soc., 55, 341-350, 1929.

Asmi, A.: Weakness of the weekend effect in aerosol number concentrations, Atmos. Environ., 51, 100-107, 2012.

Asmi, A., Wiedensohler, A., Laj, P., Fjaeraa, A.-M., Sellegri, K., Birmili, W., Weingartner, E., Baltensperger, U., Zdimal, V., Zikova, N., Putaud, J.-P., Marinoni, A., Tunved, P., Hansson, H.C., Fiebig, M., Kivekäs, N., Lihavainen, H., Asmi, E., Ulevicius, V., Aalto, P. P., Swietlicki, E., Kristensson, A., Mihalopoulos, N., Kalivitis, N., Kalapov, I., Kiss, G., de Leeuw, G., Henzing, B., Harrison, R. M., Beddows, D., O'Dowd, C., Jennings, S. G., Flentje, H., Weinhold, K., Meinhardt, F., Ries, L., and Kulmala, M.: Number size distributions and seasonality of submicron particles in Europe 2008-2009, Atmos. Chem. Phys., 11, 5505-5538, doi:10.5194/acp-11-5505-2011, 2011.
Barmet, P., Kuster, T., Muhlbauer, A., and Lohmann, U.: Weekly cycle in particulate matter versus weekly cycle in precipitation over Switzerland, J. Geophys. Res., 114, D05206, doi:10.1029/2008JD011192, 2009.

Bäumer, D. and Vogel, B.: An unexpected pattern of distinct weekly periodicities in climatological variables in Germany, Geophys. Res. Lett., 34, L03819, doi:10.1029/2006GL028559, 2007.

Bäumer, D. and Vogel, B.: Reply to comment by H. J. Hendricks Franssen on "An unexpected pattern of distinct weekly periodicities in climatological variables in Germany", Geophys. Res. Lett., 35, L05803, doi:10.1029/2007GL032432, 2008.

Bäumer, D., Rinke, R., and Vogel, B.: Weekly periodicities of Aerosol Optical Thickness over Central Europe - evidence of an anthropogenic direct aerosol effect, Atmos. Chem. Phys., 8, 83-90, doi:10.5194/acp-8-83-2008, 2008.

Beirle, S., Platt, U., Wenig, M., and Wagner, T.: Weekly cycle of $\mathrm{NO}_{2}$ by GOME measurements: a signature of anthropogenic sources, Atmos. Chem. Phys., 3, 2225-2232, doi:10.5194/acp3-2225-2003, 2003.

Bell, T. L.: Theory of optimal weighting of data to detect climatic change, J. Atmos. Sci., 43, 1694-1710, 1986.

Bell, T. L. and Rosenfeld, D.: Comment on "Weekly precipitation cycles? Lack of evidence from United States surface stations" by D. M. Schultz et al., Geophys. Res. Lett., 35, L09803, doi:10.1029/2007GL033046, 2008.

Bell, T. L., Rosenfeld, D., Kim, K. M., Yo, J. M., Lee, M. I., and Hahnenberger, M.: Midweek increase in U.S. summer rain and storm heights suggests air pollution invigorates rainstorms, J. Geophys. Res., 113, D02209, doi:10.1029/2007JD008623, 2008.

Bell, T. L., Rosenfeld, D., and Kim, K. M.: Weekly cycle of lightning: Evidence of storm invigoration by pollution, Geophys. Res. Lett., 36, L23805, doi:10.1029/2009GL040915, 2009a.

Bell, T., Yoo, J. M., and Lee, M. I.: Note on the weekly cycle of storm heights over the southeast United States, J. Geophys. Res., 114, D15201, doi:10.1029/2009JD012041, 2009b.

Cerveny, R. S. and Balling, R. C.: Weekly cycles of air pollutants, precipitation and tropical cyclones in the coastal NW Atlantic region, Nature, 394, 561-563, 1998.

Cerveny, R. S. and Balling, R. C.: Lunar influence on diurnal temperature range, Geophys. Res. Lett., 26, 1605-1607, 1999.

Cerveny, R. S. and Balling, R. C.: Variations in the diurnal character of tropical cyclone wind speeds, Geophys. Res. Lett., 32, L06706, doi:10.1029/2004GL021177, 2005.

Charlson, R. J., Schwartz, S. E., Hales, J. M., Cess, R. D., Coakley, J. A., Hansen Jr., J. E., and Hoffman, D. J.: Climate forcing by anthropogenic aerosols, Science, 255, 423-430, 1992.

Choi, Y.-S., Ho, C.-H., Chen, D., Noh, Y.-H., and Song C.-K.: Spectral analysis of weekly variation in $\mathrm{PM}_{10}$ mass concentration and meteorological conditions over China, Atmos. Environ., 42, 655666, 2008a.

Choi, Y. S., Ho, C. H., Kim, B. G., and Hur, S. K.: Long-term variation in midweek/weekend cloudiness difference during summer in Korea, Atmos. Environ., 42, 6726-6732, 2008b.

Cleveland, W. S., Graedel, T. E., Kleiner, B., and Warner, J. L.: Sunday and workday variations in photochemical air pollutants in New Jersey and New York, Science, 186, 1037-1038, 1974.

Daniel, J. S., Portmann, R. W., Solomon, S., and Murphy D. M.: Identifying weekly cycles in meteorological variables: The importance of an appropriate statistical analysis, J. Geophys. Res., 
doi:10.1029/2012JD017574, 2012.

DeLisi, M. P., Cope, A. M., and Franklin, J. K.: Weekly precipitation cycles along the northeast corridor?, Weather Forecast., 16, 343-353, 2001.

Dessens, J., Fraile, R., Pont, V., and Sanchez, J. L.: Day-of-the week variability of hail in southwestern France, Atmos. Res., 59-60, 63-76, 2001.

Dickersin, K., Chan, S., Chalmers, T. C., Sacks, H. S., and Smith, H.: Publication bias and clinical trials, Control. Clin. Trials, 8, 343-353, 1987.

Easterbrook, P. J., Berlin, J. A., Gopalan, R., and Matthews, D. R.: Publication bias in clinical research, Lancet, 337, 867-872, 1991.

Elkus, B. and Wilson, K. R: Photochemical air pollution: Weekendweekday differences, Atmos. Environ., 11, 509-515, 1977.

Forster, P. M. and Solomon, S.: Observations of a "weekend effect" in diurnal temperature range, P. Natl. Acad. Sci. USA, 100, 11225-11230, 2003.

Fujibe, F.: Day-of-the-week variations of urban temperature and their long-term trends in Japan, Theor. Appl. Climatol., 102, 393-401, 2010.

Georgoulias, A. K. and Kourtidis, K. A.: On the aerosol weekly cycle spatiotemporal variability over Europe, Atmos. Chem. Phys., 11, 4611-4632, doi:10.5194/acp-11-4611-2011, 2011.

Georgoulias, A. K. and Kourtidis, K. A.: A high resolution satellite view of the aerosol weekly cycle variability over Central Europe, Atmos. Res., 107, 145-160, 2012.

Gilge, S., Plass-Duelmer, C., Fricke, W., Kaiser, A., Ries, L., Buchmann, B., and Steinbacher, M.: Ozone, carbon monoxide and nitrogen oxides time series at four alpine GAW mountain stations in central Europe, Atmos. Chem. Phys., 10, 12295-12316, doi:10.5194/acp-10-12295-2010, 2010.

Gong, D.-Y., Guo, D., and Ho, C.-H.: Weekend effect in diurnal temperature range in China: Opposite signals between winter and summer, J. Geophys. Res., 111, D18113, doi:10.1029/2006JD007068, 2006.

Gong, D., Ho, C., Chen, D., Qian, Y., Choi, Y., and Kim, J.: Weekly cycle of aerosol-meteorology interaction over China, J. Geophys. Res., 112, D22202, doi:10.1029/2007JD008888, 2007.

Gordon, A. H.: Weekdays warmer than weekends?, Nature, 367, 325-326, 1994.

Grant, A. N., Pszenny, A. A. P, and Fischer, E. V.: The 1935-2003 Air Temperature Record from the Summit of Mount Washington, New Hampshire, J. Climate, 18, 4445-4453, 2005.

Haagen-Smit, A. and Brunelle, M. F.: The application of phenolphthalin reagent to atmospheric oxidant analysis, Int. J. Air Poll., 1, 51-59, 1958 .

Hasselmann, K.: On the signal-to-noise problem in atmospheric response studies, in: Meteorology Over the Tropical Oceans, edited by: Shaw, D. B., Royal Meteorological Society, 251-259, 1979.

Hayn, M., Beirle, S., Hamprecht, F. A., Platt, U., Menze, B. H., and Wagner, T.: Analysing spatio-temporal patterns of the global $\mathrm{NO}_{2}$-distribution retrieved from GOME satellite observations using a generalized additive model, Atmos. Chem. Phys., 9, 64596477, doi:10.5194/acp-9-6459-2009, 2009.

Hendricks Franssen, H.: Comment on "An unexpected pattern of distinct weekly periodicities in climatological variables in Germany" by Dominique Bäumer and Bernhard Vogel, Geophys. Res. Lett., 35, L05802, doi:10.1029/2007GL031279, 2008.
Hendricks Franssen, H. J., Kuster T., Barmet P., and Lohmann, U.: Comment on "Winter 'weekend effect' in southern Europe and its connection with periodicities in atmospheric dynamics" by A. Sanchez-Lorenzo et al., Geophys. Res. Lett., 36, L13706, doi:10.1029/2008GL036774, 2009.

Heuss, J. M., Kahlbaum, D. F., and Wolff, G. T.: Weekday/weekend ozone differences: what can we learn from them?, J. Air Waste Manage., 53, 772-788, 2003.

Ho, C. H., Choi, Y. S., and Hur, S. K.: Long-term changes in summer weekend effect over northeastern China and the connection with regional warming, Geophys. Res. Lett., 36, L15706, doi:10.1029/2009GL039509, 2009.

Jin, M., Shepherd, J. M., and King, M. D.: Urban aerosols and their variations with clouds and rainfall: A case study for New York and Houston, J. Geophys. Res., 110, D10S20, doi:10.1029/2004JD005081, 2005.

Kanda, M.: Progress in Urban Meteorology: a review, J. Meteorol. Soc. Jpn., 85B, 363-383, 2007.

Kaufmann, R. K., Seto, K. C., Schneider, A., Liu, Z., and Zhou, L.: Climate response to rapid urban growth: evidence of a humaninduced precipitation deficit, J. Climate, 20, 2999-2306, 2007.

Kim, B.-G., Choi, M.-H., and Ho, C.-H.: Weekly periodicities of meteorological variables and their possible association with aerosols in Korea, Atmos. Environ., 43, 6058-6065, 2009.

Kim, K. Y. and Roh, J. W.: Physical mechanisms of the wintertime surface air temperature variability in South Korea and the near7-day oscillations, J. Climate, 23, 2197-2212, 2010.

Kim, K. Y., Park, R., Kim, K. R., and Na, H.: Weekend effect: Anthropogenic or natural?, Geophys. Res. Lett., 37, L09808, doi:10.1029/2010GL043233, 2010.

Koren, I., Kaufman, Y. J., Rosenfeld, D., Remer, L. A., and Rudich, Y.: Aerosol invigoration and restructuring of Atlantic convective clouds, Geophys. Res. Lett., 32, L14828, doi:10.1029/2005GL023187, 2005.

Lacke, M. C., Mote, T. L., and Shepherd, J. M.: Aerosols and associated precipitation patterns in Atlanta, Atmos. Environ., 43, 4359-4373, 2009.

Lawrence, E. N.: Urban climate and day of the week, Atmos. Environ., 5, 935-948, 1971.

Laux, P. and Kunstmann, H.: Detection of regional weekly weather cycles across Europe, Environ. Res. Lett., 3, 044005, doi:10.1088/1748-9326/3/4/044005, 2008.

Lenschow, D. H.: Next stop for weekday warming, Nature, 369, p. 193, 1994.

Liu, Y. and Daum, P. H.: Indirect warming effect from dispersion forcing, Nature, 419, 580-581, 2002.

Lohmann, U.: A glaciation indirect aerosol effect caused by soot aerosols, Geophys. Res. Lett., 29, 1052, doi:10.1029/2001GL014357, 2002.

Lohmann, U. and Feichter, J.: Global indirect aerosol effects: a review, Atmos. Chem. Phys., 5, 715-737, doi:10.5194/acp-5-7152005, 2005.

Marani, M.: The detection of weekly preferential occurrences with an application to rainfall, J. Climate, 23, 2379-2387, 2010.

Mullayarov, V. A., Karimov R. R., Kozlov V. I., and Poddelsky, I. N.: Possible weekly variations in the thunderstorm activity, J. Atmos. Sol.-Terr. Phy., 67, 397-403, 2005.

Murphy, D. M., Capps, S. L., Daniel, J. S., Frost, G. J., and White, W. H.: Weekly patterns of aerosol in the United States, 
Atmos. Chem. Phys., 8, 2729-2739, doi:10.5194/acp-8-27292008, 2008.

Pincus, R. and Baker, M. B.: Effect of precipitation on the albedo susceptibility of clouds in the marine boundary layer, Nature, 372, 250-252, 1994.

Quaas, J., Boucher, O., Jones, A., Weedon, G. P., Kieser, J., and Joos, H.: Exploiting the weekly cycle as observed over Europe to analyse aerosol indirect effects in two climate models, Atmos. Chem. Phys., 9, 8493-8501, doi:10.5194/acp-9-8493-2009, 2009.

Rosenfeld, D. and Bell, T. L.: Why do tornados and hailstorms rest on weekends?, J. Geophys. Res., 116, D20211, doi:10.1029/2011JD016214, 2011.

Rosenfeld, D., Lohmann, U., Raga, G. B., O’Dowd, C. D., Kulmala, M., Fuzzi, S., Reissell, A., and Andreae, M. O.: Flood or drought: how do aerosols affect precipitation?, Science, 321, 1309-1313, 2008.

Sanchez-Lorenzo, A., Calbó, J., Martin-Vide, J. Garcia-Manuel, A., García-Soriano, G., and Beck, C.: Winter "weekend effect" in Southern Europe and its connections with periodicities in atmospheric dynamics, Geophys. Res. Lett., 35, L15711, doi:10.1029/2008GL034160, 2008.

Sanchez-Lorenzo, A., Calbó, J., and Martin-Vide, J.: Reply to comment by H. J. Hendricks Franssen et al. on "Winter "weekend effect' in southern Europe and its connections with periodicities in atmospheric dynamics", Geophys. Res. Lett., 36, L13707, doi:10.1029/2009GL038041, 2009.

Schultz, D. M., Mikkonen, S., Laaksonen, A., and Richman, M. B.: Weekly precipitation cycles? Lack of evidence from United States surface stations, Geophys. Res. Lett., 34, L22815, doi:10.1029/2007GL031889, 2007.

Shutters, S. T. and Balling., R. C.: Weekly periodicity of environmental variables in Phoenix, Arizona, Atmos. Environ., 40, 304310,2006

Simmonds, I. and Keay, K.: Weekly cycle of meteorological variations in Melbourne and the role of pollution and anthropogenic heat release, Atmos. Environ., 31, 1589-1603, 1997.

Sitnov, S. A.: Weekly cycle of meteorological parameters over Moscow Region, Dokl. Earth Sci., 431, 507-513, 2010.

Sitnov, S. A.: Weekly variations in temperature and precipitation in Moscow: relation with weekly cycles of air pollutants and synoptic variability, Izv. Atmos. Ocean. Phys., 47, 445-456, 2011 a.
Sitnov, S. A.: Aerosol optical thickness and the total carbon monoxide content over the European Russia territory in the 2010 summer Period of mass fires: interrelation between the variation in pollutants and meteorological parameters, Izv. Atmos. Ocean. Phys., 47, 714-728, $2011 \mathrm{~b}$.

Small, J. D., Chuang, P. Y., Feingold, G., and Jiang, H.: Can aerosol decrease cloud lifetime?, Geophys. Res. Lett., 36, L16806, doi:10.1029/2009GL038888, 2009.

Solomon, S., Qin, D., Manning, M., Chen, Z., Marquis, M., Averyt, K., Tignor, M., and Miller, H. (Eds.): Climate Change 2007 : The Physical Science Basis. Contribution of Working Group I to the Fourth Assessment Report of the Intergovernmental Panel on Climate Change, Cambridge University Press, Cambridge, United Kingdom and New York, NY, USA, 2007.

Stevens, B. and Feingold, G.: Untangling aerosol effects on clouds and precipitation in a buffered system, Nature, 461, 607-613, 2009.

Stjern, C. W.: Weekly cycles in precipitation and other meteorological variables in a polluted region of Europe, Atmos. Chem. Phys., 11, 4095-4104, doi:10.5194/acp-11-4095-2011, 2011.

Svoma, B. M. and Balling, R. C.: An anthropogenic signal in Phoenix, Arizona winter precipitation, Theor. Appl. Climatol., 98, 315-321, 2009.

Tesouro, M., De La Torre, L., Nieto, R., Gimeno, L., Ribera, P., and Gallego, D.: Weekly cycle in NCAR-NCEP reanalysis surface temperature data, Atmosfera, 18, 205-209, 2005.

Tuttle, J. D. and Carbone, R. E.: Inferences of weekly cycles in summertime rainfall, J. Geophys. Res., 116, D20213, doi:10.1029/2011JD015819, 2011.

Twomey, S.: Pollution and the planetary albedo, Atmos. Environ., 8, 1251-1256, 1974.

Wilks, D. S.: On "field significance" and the false discovery rate, J. Appl. Meteor. Climatol., 45, 1181-1189, 2006.

Xia, X., Eck, T. F., Holben, B. N., Phillippe, G., and Chen, H.: Analysis of the weekly cycle of aerosol optical depth using AERONET and MODIS data, J. Geophys. Res., 113, D14217, doi:10.1029/2007JD009604, 2008.

You, Q., Kang, S., Flugel, W. A., Sanchez-Lorenzo, A., Yan, Y., Xu, Y., and Huang, J.: Does a weekend effect in diurnal temperature range exist in the eastern and central Tibetan Plateau?, Environ. Res. Lett., 4, 045202, doi:10.1088/1748-9326/4/4/045202, 2009. 